\title{
New Setting, Same Skill: Teaching Geography Students to Transfer Information Literacy Skills From Familiar to Unfamiliar Contexts
}

\author{
Caleb Allison \\ Faculty of Education, University of Auckland, New Zealand \\ Kumar Laxman (Corresponding author) \\ Faculty of Education, University of Auckland, New Zealand \\ E-mail: haribol.kumar@gmail.com \\ Mei Lai \\ Faculty of Education, University of Auckland, New Zealand
}

Received: 16-03- 2016

doi:10.7575/aiac.ijels.v.4n.2p.27
Accepted: 18-04-2016

URL: http://dx.doi.org/10.7575/aiac.ijels.v.4n.2p.27
Published: 30-04-2016

\begin{abstract}
Existing research shows that high school students do not possess information literacy skills adequate to function in a high-tech society that relies so heavily on information. If students are taught these skills, they struggle to apply them. This small-scale intervention focused on helping Geography students at a low-socioeconomic high school in Auckland, New Zealand to transfer information literacy skills from familiar to unfamiliar topics. It tested whether teaching information literacy skills via direct instruction, and then giving students the opportunity to use these skills in structured practice sessions online, would help them transfer those skills. The need for the study arose from a gap in existing research into teaching information literacy for transfer. The findings of this study indicated that it was relatively easy for the students to learn to formulate search queries, but they need more help evaluating information sources. The findings also showed that direct feedback from a teacher is vital to teaching information literacy. The findings are significant in that they add to a growing body of research that teaching information literacy through practical research projects is potentially more effective than decontextualising the skills and teaching them as a standalone topic. Furthermore, the findings support existing research that teacher feedback is a necessary component of teaching information literacy.
\end{abstract}

Keywords: Geography education, Information literacy skills

\section{Introduction}

With the internet being prolific in many aspects of society today, information literacy skills are vital to students who want to succeed. Google is a default portal for many students who want to find a piece of information, but existing studies show it is generally not being used effectively as a research tool. This study investigated the teaching of information literacy skills to high school Geography students. It sought to find out whether using direct instruction as a teaching method, coupled with structured practice, could help students transfer information literacy skills from familiar to unfamiliar contexts. The research process involved the student researcher delivering lessons to the participants on how to conduct an effective search query, and how to evaluate sources of information. Students then participated in a series of practice sessions whereby they answered complex research questions using the skills they had been taught in the direct instruction lessons. Their activities were evaluated by the first author to see how their skills developed over the course of the intervention.

We know from existing research that information literacy skills are lacking in high school students (Scott \& Sullivan, 2005; Martin, Garcia \& McPhee, 2012; Head, 2013). It is also clear that teaching information literacy requires a combination of direct instruction and opportunities to practice the skills (Bransford, Brown \& Cocking, 1999; Reece, 2007; Thomas, Crow and Franklin, 2011). However, what is not explained by existing research is whether these methods can help students transfer information literacy skills from familiar to unfamiliar topics. While this has not been tested, it is known that transfer occurs when students are given a range of contexts in which to apply a skill or concept (Andrews, 2002). When students practice in a "variety of somewhat related and expanding contexts", it makes it more likely that transfer from the familiar to the unfamiliar will occur because "a new circumstance would excite procedures many of which had worked together before" (Salomon \& Perkins, 1989, p. 120). Therefore, the hypothesis of this study is that by combining the methods of direct instruction and structured practice sessions, the results will demonstrate that transfer has occurred by showing an improvement in the effectiveness of participant searches over the five-week 
intervention.

\section{Research Purpose}

This study focused on teaching high school Geography students to transfer information literacy skills from familiar to unfamiliar contexts. The need for the study stems from existing research which shows students have underdeveloped information literacy skills (Scott \& Sullivan, 2005; Gross \& Latham, 2007; Katz, 2007). The goal of this study was that with the use of practice sessions to help students put their newly-learnt skills into action, they would be able to transfer these skills. Thus, the research question this study aims to answer is:

- How can direct instruction and structured practice enable senior High School Geography students to transfer information literacy skills from familiar to unfamiliar topics?

\section{Literature Review}

The internet has become the primary tool through which high school students search for information, but most students do not know how to search effectively or determine the reliability of sources (Scott \& Sullivan, 2005). Because today's students are generally computer-literate, they also assume they are information-literate, despite evidence suggesting students greatly overestimate their information literacy skills (Manuel, 2002). This has particularly serious implications for students who go on to university, as their lack of information literacy leaves them unprepared for the vast amounts of information they will need to evaluate as part of their tertiary study (Martin, et al., 2012; Head, 2013; O'Sullivan \& Dallas, 2010; Varlejs \& Stec, 2014).

The lack of information literacy skills by high school students is supported by research. A 2006 study of almost 6400 high-school and university students in the United States - who undertook online tests of their information literacy skills - found "evidence consistent with anecdotal reports" that students are woefully unskilled in information literacy (Katz, 2007, p. 11). Similarly, Kovalik's (2013) study into how 289 high school seniors in the US were prepared for college in terms of their information literacy skills found most students had a good grasp of the basics, but struggled to effectively evaluate sources and determine the validity of information, both key components of information literacy. The implications of students reaching adulthood with limited information literacy skills could be serious, inhibiting their ability to succeed in an increasingly information-rich society (Gross \& Latham, 2007).

\subsection{Defining information literacy}

There have been many attempts to define information literacy over the past several decades. The term was first coined by Zurkowski in 1974 when he recommended the US government establish a national programme to promote workrelated information literacy (Webber \& Johnston, 2000). One of the most commonly-cited definitions is from Doyle's (1992) report to the National Forum on Information Literacy, where information literacy is defined as "the ability to access, evaluate, and use information from a variety of sources" (p. 1). The American Library Association (2000) uses a similar definition, but adds that an information literate person knows when information is needed. Lenox and Walker (1993) have also defined information literacy: they argue an information literate person can formulate research questions, find the answers, critically evaluate the results, and then assess them.

\subsection{The role of direct instruction in teaching information literacy skills}

Many researchers agree that direct instruction has a role to play in teaching information literacy, but only under certain conditions. A danger of using direct instruction as a teaching method is that students can form misconceptions that hinder their learning, but, if used in conjunction with other methods, it can be highly effective (Bransford, et al., 1999). In their analysis of studies comparing unguided to guided instruction, Kirschner, Sweller \& Clark (2006) argue there is clear evidence that direct instruction leads to greater learning and transfer. Similarly, Reece (2007) argues that direct instruction, linked with opportunities to practice, must be a part of any successful information literacy teaching programme. He claims that because information literacy is complex and synonymous with higher-order thinking, students must be taught information literacy skills directly first (Reece, 2007). Research by Serrell (2009) echoes this need for direct instruction to be coupled with opportunities to practice. Her study of teaching information literacy skills to primary school children found students picked up the basics of information literacy from being taught directly, but their skills did not develop as much as those that practiced their skills in a project- based setting (Serrell, 2009).

\subsection{The role of structured practice in teaching information literacy skills}

There is clear evidence that opportunities to practice a skill is a vital part of learning. As with learning any skill, acting on knowledge is an important part of the process (DeLay, 1996; Piaget, 1964). To maximise the potential for learning, practice must be varied enough that when the learner encounters a new situation, they may recall procedures they have done in past experiences (Salomon \& Perkins, 1989). This is particularly true for learning information literacy, as becoming immersed in the research process is considered by many researchers to be the best way to learn these skills (Fabbi, 2015).

Recent studies support the need for information literacy to be taught primarily through practice. O'Sullivan and Dallas' (2010) study into incorporating advanced information literacy skills into the high school curriculum found that by requiring students to actively engage in research culminating with an assignment, the students were better prepared for the intellectual demands of university (O'Sullivan \& Dallas, 2010). Another study, albeit with second-year university students, found similar results: a one-hour-per-week course at the University of North Alabama taught students how to 
find information in databases and search engines, analyse the relevance of information, and determine whether sources were primary or secondary (Thompson \& Blankinship, 2015). A core part of the course was that students practiced their skills as part of assignments in information literacy. The researchers found that having the opportunity to practice was vital for the students to learn information literacy skills (Thompson \& Blankinship, 2015). A similar study, this time with primary school students, found that by teachers incorporating the teaching of information literacy skills into student group projects, the students were better able to learn these skills (Chu, Tse \& Chow, 2011). The approach comes under the term 'project-based learning', during which students work towards projects that explore issues, themes or problems without predefined answers (Chu, et al., 2011).

\subsection{Transfer of information literacy skills}

Because the aim of information literacy is to enable people to evaluate unfamiliar sources of information, transfer is a vital part of teaching information literacy skills (Reece, 2007). When it comes to finding new information, students often fail to transfer what they have learned previously in different contexts (Walton \& Archer, 2004). Much of the research into transfer supports the concept that students transfer knowledge more readily when they are given casebased reasoning (Andrews, 2002). However, the skill of transfer must also be taught specifically to students: for example, by offering a range of case studies on a topic, students can be encouraged to identify similarities between them, thereby helping them to form connections between familiar and unfamiliar contexts (Salomon \& Perkins, 1989). This "abstraction" is what Salomon and Perkins (1989) term "high-road" transfer, whereby students are given "explicit instruction aimed at provoking or conveying well-understood abstractions" (p. 127). This differs from low-road transfer, which is when a "performance is unintentional, implicit, based on modelling and driven by reinforcement" (p. 127). This notion of explicitly teaching transfer skills is supported by Reece (2007), who notes that with reference to information literacy, students need to be specifically instructed in how to apply information literacy skills to new contexts.

\section{Method}

The design of this project was that of a small-scale intervention study. The study was conducted qualitatively through interviews and questionnaires as such an approach is vital to providing a more holistic understanding of how well this intervention works. The interviews aimed to reveal how the students felt about the process and their own skills, while the questionnaires would provide insight into their metacognitive processes.

\subsection{Participants}

The participants were three Year 12 (16-17 years old) students of one Geography class at a low-decile secondary school in east Auckland. In New Zealand, decile refers to the relative wealth of the community in which the school is based, so a low- decile school is one that serves a low-socioeconomic community (Ministry of Education, 2015). At this school, Year 12 students participate in the secondary school qualification administered by the New Zealand Qualifications Authority (NZQA), National Certificate of Educational Achievement (NCEA). The participants - all from Pacific Island backgrounds - were students of the student researcher, who was their regular Geography teacher. The participants were Geography students because in this subject students needed to be able to "obtain, present and analyse information" from a variety of sources (Ministry of Education, 2013). These are skills developed through information literacy. Year 12 (NCEA Level 2) students were chosen because the first author, as the teacher of geography at the school at this level, identified problems among students at this level with basic information literacy skills. The school these students attended utilised digital devices in the form of laptops as the primary learning tool for all students, meaning searching for information online was a common occurrence in their classroom. Participants were chosen at random from a selection of students who believed they had trouble finding information online and determining its reliability. All students in the class were invited at the beginning of the study to indicate if they had trouble finding information online and would like to improve these skills by participating in the study. Those that indicated in the affirmative were selected as potential participants, and the final participants were randomly selected by the Principal Investigator from this group.

\subsection{Setting}

The setting for this study was the regular NCEA Level 2 Geography classroom of one low-decile secondary school in east Auckland. A "low-decile" school is one that draws from predominantly low-socioeconomic communities (Ministry of Education, 2015). The school is one of 11 in a cluster of schools in which teaching and learning is predominantly facilitated through the use of digital devices. The schools are 1:1, meaning each student has access to their own digital device. Students generally also have access to the internet at home through a wireless network that offers free coverage for students throughout the community. As this study is focused on online information literacy, it was pertinent to conduct it in a community where searching for information online is commonplace. Furthermore, research so far suggests despite having access to digital devices, many high school students lack the advanced information literacy skills necessary to maximise their use of the internet as a learning tool (Scott \& Sullivan, 2005).

\subsection{Measures}

This study comprised two main elements: direct instruction lessons, whereby students were taught explicitly about how to search effectively using Google (information literacy skills); and practice sessions, during which students answered challenging questions using Google and the skills they were taught during the direct instruction lessons. The students' answers to the questions formed part of the data to be analysed. 
Qualitative data was recorded in the form of an initial interview, and five questionnaires (one after each practice session). The students' responses during the interviews and questionnaires were put into a Google Form, which was then collated into a spreadsheet.

The initial interview asked students:

- Do you have internet access at home?

- If not, where do you access the internet?

- If so, how much do you use the internet?

- What activities do you use the internet for?

- How often do you use the Google search engine to look for information?

- Have you received teaching on how to search for information on the internet?

These questions were asked in order to gauge the level of experience using the internet and Google to see if there is a relationship between this and the students' information literacy skills. While this study does not directly address the issue of internet experience on information literacy, existing research suggests internet experience can explain why some students fail to effectively search for information online (Lei, Lin \& Sun, 2013).

The questionnaires were administered to students via a Google Form after each practice session, and were completed immediately by each student present during that practice session. The questions were designed by the first author, and the questions were the same for each questionnaire the students completed. The questionnaire asked students:

- Think of the last time you conducted a search using the Internet. How did you decide which words you used in the initial search query?

- On a scale of 1 to 5 ( 5 being very effective, 1 being not effective at all) how effective do you think your internet searches were today?

- Think of one of the websites you visited today during your search. How did you decide how reliable or unreliable that website was?

- Think of an instance today where you had to re-do a search. How did you do it differently the second time?

- Which question was the easiest for you to answer? Why?

These questions were designed to encourage the students to reflect on their searches and consider what they could have done differently. Adding this metacognitive component is vital to the learning of information literacy skills, as practice alone is unlikely to result in effective transfer. The questionnaires were administered via Google Forms so the students could complete them when they were ready.

The direct instruction lessons comprised two 30-minute lessons: the first aimed to teach students that the search queries used in Google would affect their results, while the second focused on interpreting the search results to find the answer to a problem. The direct instruction lessons were conducted within the students' regular Geography class, and were delivered to all students in the class. This was so as not to exclude any students from the potential benefits of the lessons. The lessons were adapted from a series of free lessons developed by Google, called Google Search Education. The lessons were changed to cater to the individual needs of the class. For example, in Google's first lesson, it refers to finding information about Percy Jackson books. The first author changed this to be about Harry Potter, a series of books the students in this study would be more likely to be familiar with. Furthermore, Google's suite of lessons contained 15 lessons in total, ranging from beginner to advanced stage, and covering all aspects of information literacy.

In the first lesson, students were taught explicitly not to simply enter a question into the Google search box as Google does not read the entire search query, but rather scans the query for keywords. Students were instructed to think carefully about what information Google needs in order to find the answer to a query and enter only the most important words relating to that query. During the second lesson, students were introduced to the search results Google offers after making a query. They were instructed to examine the information given in the results and predict what sort of information is likely to be on that page based on the URL, the title of the page and the abstract given in the results. Thus, if a search is done effectively, the students would only need to visit one or two websites because they would already have an idea of whether that page would yield relevant information.

Considering the limited scope of this study and the need to contain these lessons within existing classroom teaching time, the researchers chose to focus only on teaching two of the most basic elements of information literacy skills: using the right search query and understanding search results.

Following the first direct instruction lesson, the participants returned to the class during lunchtime the following day to practice what they had been taught. They were given five questions written by the student researcher on a range of topics. All students received the same questions. Students had 30-minutes to answer the questions using Google. To monitor their activities, the screens of the computers the students were using were recorded during the practice session using the screen capture software Screencastify. This method was preferred to observations due to the logistical difficulties of monitoring the computers of several students at once. 
The questions given to the students were designed to be difficult to answer if the whole question was simply copied and pasted into the Google search bar. For example, the question "Of which New Zealand band was Malcolm Green the drummer during the 1970s and 1980s?" does not yield an accurate result if it is entered in its entirety. Instead, students are forced to select the keywords of the question and form a search query out of them. The following week, the students returned for another practice session conducted in the same way, albeit with a different set of questions. During the intervention, the direct instruction lessons were taught on the Thursdays of Week One and Week Three. The practice sessions took place during lunchtime each Friday.

To measure how students' information literacy skills developed over the five weeks, data was collected by recording: the search terms they used; the websites they visited; and how many attempts they needed to answer the question. While these three elements are only a small portion of what constitutes information literacy, they are important skills that indicate the level of a student's information literacy development (Doyle, 1992; American Library Association, 2000; Breivik, 2005). Following each practice session the student researcher watched the footage from the screen capture recordings and entered the information into a table in a Google Docs document. A new table was used for each student and each practice session. Each table contained the five challenge questions for each practice session, and next to each question were columns that recorded the search terms they used for each attempt; the websites visited; and whether or not they had successfully found the answer to the question.

The problem of transferring skills from familiar to unfamiliar contexts is at the centre of this study. As Salomon and Perkins (1989) note, transfer from familiar to unfamiliar contexts occurs when a person has practice in enough related but "expanding" contexts so as to draw on past experience when faced with a new situation (p. 120). In this study, the "related" aspect was the situation of sitting at a computer and using Google to find out information. The "expanding" aspect was the questions: each question was different and unfamiliar, leading students to draw on their previous experiences to find relevant pieces of information. To determine whether a topic was likely to be unfamiliar, the researchers used their knowledge of the students to carefully select questions about topics they were likely to be unfamiliar with. Thus, by providing students with a range of questions on unfamiliar topics, transfer would occur if they applied their information literacy skills to finding out information on those new topics.

\subsection{Analysis}

The relatively small sample size of the study, coupled with some participants withdrawing from the study and others not completing it, means case study analysis is the most appropriate form for the data collected.

While the initial plan called for five students to take part in five practice sessions over a five-week period, two participants had withdrawn before the first practice session was held. Those participants did not give reasons for their withdrawal. Of the remaining three participants, one attended one practice session and the first direct instruction lesson, the second attended three practice sessions and both direct instruction lessons, and the third participant took part in four practice sessions and both direct instruction lessons. This variation makes comparing the results in a data table difficult, as the data would not be uniform.

To judge whether the participants' searches became more effective over the course of the study, each search was given a number corresponding to its effectiveness:

$$
\begin{aligned}
& 3=\text { highly effective } \\
& 2=\text { somewhat effective } \\
& 1=\text { not effective }
\end{aligned}
$$

To judge how effective a search is, this study drew from the criteria used by Katz' (2007) study on testing online information literacy skills. According to Katz (2007), when a student searches for information effectively, he or she is able to:

- $\quad$ generate and combine search terms (keywords) to satisfy the requirements of a particular research task;

- $\quad$ efficiently browse one or more resources to locate pertinent information;

- $\quad$ decide which resources might yield the most useful information for a particular need.

To examine the data, the researchers entered the students' search activity into a table in a Google Doc while watching a video of their practice session. In this table they entered: each search question; any websites the student visited as they attempted to answer the question; whether or not they found the correct answer; and their overall search effectiveness score. If a student did not click on a website, but analysed the search results in an attempt to find the answer, this was noted on the table. As was often the case, students did find the answer to the question by scanning the search results without opening a website.

Evaluating the participants' search behaviour alone may not inform the research as to how well they are determining the validity of resources, so the researchers used responses from the questionnaires to inform this aspect of the study. Because it is not appropriate in this case to compare the students directly, each participant was evaluated separately. Participants are referred to as Student A, Student B and Student C. 


\section{Findings}

All three participants in this study were 16 year-olds of Pacific Island descent. Based on their initial interviews with the student researcher, all three participants had completed all of their schooling in the low-socioeconomic community in which this study was based, and all had a personal laptop (provided as part of the school's digital device programme) which they used to complete school activities and assessments. All three had internet access at home and all used the internet every day. One student reported using the internet "all the time". All participants reported using the internet predominantly for social media and school work, and all said they use Google frequently to search for information. No participant reported receiving any formal training in how to search for information using Google or any other search engine. Thus, despite being apparently well-versed in using the internet for a range of pursuits, all students felt their internet search skills were underdeveloped. Indeed, students were invited to participate in the study if they felt their internet search skills needed developing.

\subsection{Student $A$}

Student A was present in class for only the first direct instruction and attended one practice session. During the initial interview Student A revealed that he used Google frequently to search for information, but found it hard to do so. Because this student attended only one practice session (Table 1), it is not possible to see how his information literacy skills would have developed if he had continued to participate.

Table 1. Student A search data

\begin{tabular}{llllll}
\hline & \multicolumn{5}{c}{ Practice Session } \\
& 1 & 2 & 3 & 4 & 5 \\
\hline Total search attempts & 5 & No Data & No Data & No Data & No Data \\
Total search effectiveness score & 9 & & & \\
Overall search effectiveness score (total & 2 & & & \\
search effectiveness/ total search attempts) & & & & \\
\hline
\end{tabular}

In the practice session one, despite being taught during the first direct instruction lesson not to enter questions into the search box, Student A merely rephrased question one to ask: "Malcolm Green drumming band 1970s and 1980s?" This search was judged to be a 2 on the effectiveness scale, as the student used some keywords, but overall the search was too general to yield many valuable results, as the student discovered once he entered his search and failed to find the answer. He found the answer on his second attempt by entering: "Malcolm Green drumming band 1970s". This query was more effective because it reduced the number of keywords Google needed to scan in order to find an answer. Ultimately, the student would have simply entered "Malcolm Green drummer" to find a biography page on the musician, which would quickly lead to the correct answer, which was Split Enz.

On question 2, Student A gave up quickly after reading the question: "The Hindu Kush mountain range extends 500 miles westward from Pakistan to what country?" Again, attempting to rephrase the question, he entered: "The Hindu Kush mountain range extends to what countries?" This is an ineffective search because it fails to utilise keywords, or anticipate what information Google would need in order to deliver useful results. The student examined the results page and moved on to the next question without opening a single page.

When Student A got to question 3 (Which film won the Oscar for Best Picture in 1994?), he immediately entered: "Winning film for Best Picture in 1994?" However, after being prompted by the student researcher not to ask questions, he made a second attempt, this time searching: "Oscar for best film in 1994". This is an effective question because it does not ask a question and it utilises keywords. The student found the correct answer, Schindler's List, immediately after making this query.

Student A achieved an overall score of 2 for the first practice session. He did not complete a questionnaire following this practice session. The data suggests he did leave the first practice session with at least some grasp of what constituted an effective search but employing some keywords in the latter search attempts. However, it is unclear how much of these skills he possessed before going through the first direct instruction lesson. Furthermore, when beginning the first practice session by immediately employing internet search strategies he was explicitly taught not to use in the direct instruction lesson, this suggests direct instruction alone is not an effective way to teach information literacy skills.

\subsection{Student $B$}

Student B was present for both direct instruction lessons, and participated in three practice sessions (Table 2). His overall search effectiveness score over the three sessions declined from 2.75 in the first session to 1.45 in the third. However, because his score in the second session declined to 1.27 , he did show an improvement of 0.18 from the second to third session.

\subsubsection{Practice session one}

Student B achieved an overall score of 2.75 for practice session one. His searches during this practice session were 
highly effective. Although he did not complete all five questions because he ran out of time, his searches on the first four questions were generally concise and yielded the correct answer on the first attempt.

Table 2. Student B search data

\begin{tabular}{llllll}
\hline & \multicolumn{5}{c}{ Practice Session } \\
& 1 & 2 & 3 & 4 & 5 \\
\hline Total search attempts & 4 & 11 & 11 & No Data & No Data \\
Total search effectiveness score & 11 & 15 & 16 & & \\
Overall search effectiveness score (total & 2.75 & 1.27 & 1.45 & \\
search effectiveness/ total search attempts) & & & & \\
\hline
\end{tabular}

For example, for question one he searched: "Malcolm Green drummer". From there, he quickly scanned the Wikipedia page on Malcolm Green to deduce the correct answer, Split Enz. His searches for the other questions were similarly effective: "Hindu Kush range"; "Best film in 1994"; and "religious Jewish candle". All these searches utilised keywords effectively and showed a relatively advanced level of information literacy in selecting the correct web page for each search query. This is in contrast to Student A, who continued to ask questions in most of his search queries.

\subsubsection{Practice session two}

Student B achieved an overall score of 1.27 for practice session two, a significant decline from the first practice session. While still employing some of the search strategies he used successfully in the first practice session, this time he appeared to not be thinking carefully about what information Google needed in order to answer his query. For example, for question one (Of all the countries in the world, which one gets most of its energy from renewable sources?), he entered: "countries with renewable sources". Despite opening the Wikipedia page which ranks countries by renewable energy production, he quickly gave up examining the data and conducted another search, this time asking: "countries that use renewable sources". He went to two different sites: an article on the EcoWatch website with the headline, "Countries leading the way in renewable energy"; and a similar article on Care2, with a headline reading, "Countries leading the world in renewable energy". After a quick scan of both sites, he returned to the original Wikipedia page, found China at the top of the list, and entered that as the answer. However, he did not correctly identify that the table he was looking at ranked countries by total energy derived from renewable sources, not the proportion of the country's energy made from renewable sources, which is what the question asked. Student $\mathrm{C}$ also struggled with this question, suggesting the wording of the question may have been too ambiguous for students with relatively limited understanding of energy production.

Student B continued to employ similar search strategies on the remaining questions during practice session two. His search queries were good: for example, for question two he entered "oldest city inhabited in existence", and for question three he entered "popular sports in denmark". In themselves these are effective search queries: they use appropriate keywords, do not ask a question, and do not contain any superfluous words. Student B's difficulties in answering the question came in the evaluation stage, where he needed to examine sources in order to find the answer, a key component of information literacy. On question three, Student B made three unsuccessful attempts to find the answer before entering "third most popular sports in denmark", which is a less effective search query than his others, but yielded him a result because it led him to the Wikipedia page on sports in Denmark, and then to the correct answer, Gymnastics. It should be noted that at this stage, Student B had not received the second direct instruction lesson on evaluating search results.

In the questionnaire following this practice session, Student B noted his searches were not as effective as in the previous practice session, giving himself a rating of two out of five for this day's searches. In response to the question asking what he could have done differently when he had to conduct a re-search, the student said he could "use keywords instead of asking Google a question". This shows the student had indeed learnt something from the first direct instruction lesson, during which this concept was taught explicitly. However, this did not appear to be a problem this student had: not once did he simply enter an entire question into Google, suggesting he may have learnt the concept but was not applying it to his own practice.

\subsubsection{Practice session three}

Student B's overall score of 1.45 for practice session three possibly reflects the fact that by this stage, he had been through both direct instruction lessons on searching for information online. Thus, he had the benefit of two practice sessions and the explicit teaching of search and evaluation strategies. As in practice session two, Student B showed a propensity towards careless evaluation of results rather than inadequate search queries. For example, his search queries for the first two questions in this session were "Home of Rugby League in Aucklnd (sic) 2002" and "Battle of Britain". Taken in isolation, these are not bad search queries, however they required more careful examination of the results to yield an answer. For the first question, Student B briefly visited the Wikipedia page about Auckland Rugby League, but when a quick scan of the page did not yield a result, he conducted a second search query of "rugby league in Auckland" 
before quickly giving up and moving on to the next question.

A similar lack of care was seen in question two: when trying to find out the war in which the Battle of Britain occurred, Student B searched "Battle of Britain" and quickly examined the Wikipedia page about the battle. He correctly identified that the battle happened in 1940, but failed to write down that it occurred during the Second World War, which was the correct answer. Student B also made six attempts to answer question three, which asked when Robert Laidlaw founded the Farmers Trading Company. More careful examination of the results could have led the student to the answer more quickly.

Despite less effective examination of search results during practice session two and three, the student did show some improvement from the second to the third practice session. However, due to a lack of qualitative data for this student it is difficult to determine the reasons behind his development: student B completed the post practice session questionnaire only for the second session.

5.3 Student $C$

Student $\mathrm{C}$ was present for both direct instruction lessons and attended four practice sessions. Over the four practice sessions her overall search effectiveness score increased 0.48 (Table 3 ). While her score in the final session was not her best, she showed an overall trend of improvement.

Table 3. Student C search data

\begin{tabular}{llllll}
\hline & \multicolumn{5}{c}{ Practice Session } \\
& 1 & 2 & 3 & 4 & 5 \\
\hline Total search attempts & 6 & 7 & 6 & 5 & No Data \\
Total search effectiveness score & 8 & 10 & 12 & 9 & \\
Overall search effectiveness score (total & 1.32 & 1.40 & 2 & 1.8 \\
search effectiveness/ total search attempts) & & & & & \\
\hline
\end{tabular}

\subsubsection{Practice session one.}

Student $\mathrm{C}$ achieved an overall search effectiveness score of 1.32 during practice session one, the lowest of the three participants for this session. In five of her six search attempts, she began her queries with "what" or "which", words that preempt a question. Most of these searches resulted in a search effectiveness score of 1. For example, on question one she initially entered: "What New Zealand band did Malcolm green drum for?" After quickly scanning the results and not immediately finding the answer, Student $\mathrm{C}$ decided she needed to provide more information, so she added "during 1970 s and 1980s" to the query. By her final attempt - after prompting from the student researcher - she remembered not to ask questions and attempted to use keywords instead.

\subsubsection{Practice session two.}

Student C's search effectiveness score for practice session two increased slightly 1.8 to 1.40 . Generally, her search queries were better but she did not evaluate the sources carefully in order to find the answer. However, it should be noted that this practice session took place before the second direct instruction lesson on evaluating sources had been delivered.

The student began, again, by entering a question into the search box, asking: "which country gets most of its renewable energy". Without prompting from the student researcher, she recalled the previous practice session and re-entered her query using keywords. However, her lack of analysis of the results meant she still got the answer wrong. She employed similar strategies for question two, entering: "oldest continuously inhabited city". Simply by quickly scanning the Google search results and not opening a web page, she incorrectly wrote that the answer was Varanasi.

While she did open a website for question three, she did not analyse its contents carefully enough and again, answered incorrectly.

\subsubsection{Practice session three}

Student $\mathrm{C}$ achieved an overall search effectiveness score of 2 for the third practice session, an improvement of 0.68 from the first session (Appendix 3). During this session, the student employed effective search queries and showed some analysis of sources, a skill that was taught during the direct instruction lesson delivered the day before this practice session.

While in practice sessions one and two the student showed a propensity towards giving up and moving on when the answer was not immediately apparently in the Google search results, this time she made an attempt to scan the Wikipedia page about Carlaw Park to confirm the answer was correct. Her search query of "sports ground closed 2002 auckland" was highly effective as it used only the keywords necessary, and showed the student was thinking about what information Google would need in order to answer her query. For example, she did not enter the words "rugby" or "league", possibly recognising that that would be too much information for an effective search. 
Her searches for the remaining questions were good: "battle of britain war"; "Robert Laidlaw farmers trading company"; "road james dean drove on when he died"; and "model of car popular 2014". However, her incorrect answers for the final two showed her skill of analysing sources still needed some development. For example, for question four, she correctly identified that James Dean died in Cholame, California, but did not state that the road he died on was Highway 46, which would have answered the question. The student did analyse some websites in attempting to answer this question but did not read carefully enough to answer the question.

Similarly, in question five she correctly identified the Toyota Corolla as the best- selling car, but did not realise that the website she got the information from was an Australian website, not a New Zealand site as indicated by the .com.au suffix on the site's URL. While the Toyota Corolla was indeed the most popular car in New Zealand anyway, her attempt was judged as incorrect because her finding was incidental.

\subsubsection{Practice session four}

Student $\mathrm{C}$ achieved an overall search effectiveness score of 1.8 for practice session four, an improvement of 0.48 from practice session one, but a decline of 0.02 from practice session three. Similar search strategies were seen during this practice session to the previous one, with the student conducting good search queries, but not following these through with effective analysis of results. For example, the first question required the student to first identify Liza Minelli's mother before determining which film she starred in, the answer being Judy Garland in The Wizard of Oz. In this case, Student $\mathrm{C}$ instead wrote that the film was Cabaret, a film starring Liza Minelli. To get this answer, the student went to a biography page of Liza Minelli, and did not examine its contents carefully enough to identify the information as relating to Minelli, not her mother. The student had similar difficulties with question three about the New Zealand music festival, which required the student to first identify New Zealand music festivals before determining which one began and ended in the years given in the question.

Student $\mathrm{C}$ completed the questionnaire following each practice session, but her responses show little insight into how and why she employed the strategies she did. For example, in response to question, "Think of one of the websites you visited today during your search. How did you decide how reliable or unreliable that website was?", in each questionnaire she responded that she used Wikipedia, despite its reputation as being an unreliable source of information. Similarly, in answer to the question, "Think of an instance today where you had to re-do a search. How did you do it differently the second time?", in each questionnaire she replied that she reworded the question. This lack of insightful responses potentially reflects a flaw in the questionnaire design, as the questions do not necessarily lead the respondent to carefully consider their response. Furthermore, it could indicate the need for teaching metacognitive strategies.

\section{Discussion and conclusions}

It is unclear whether direct instruction and structured practice can help high school Geography students transfer information literacy skills from familiar to unfamiliar topics. While two out of three participants did show some improvement over the course of the study, the improvement was not enough to judge that transfer occurred. Students seemed to gain some basic knowledge of information literacy as a result of the direct instruction lessons, but they struggled to appropriately evaluate sources when it came to the practice sessions. This is consistent with existing research that students can learn how to search appropriately without too much effort, but they find it more difficult to learn to analyse information (Kovalik, 2013). The results also support existing research that high school students generally lack information literacy skills and struggle to apply them (Scott \& Sullivan, 2005; Martin, et al., 2012; Head, 2013).

A key aspect of this study was whether students could be taught to transfer information literacy skills, but it is unclear from the results if this occurred. There is evidence of some "low road" transfer, with Student C learning in the first practice session to formulate a search query using keywords, a strategy she continued to employ throughout the remaining three practice sessions. This could be categorised as "low road" transfer in that the task of formulating a search query is relatively "automatic" and required little depth of thought (Salomon \& Perkins, 1989, p. 118). There is little evidence, however, that "high road" transfer occurred. "High road" tasks are more analystical, abstract and require linking back to prior experiences, which is consistent with evaluating search results (Salomon \& Perkins, 1989). This is the aspect of information literacy the participants had the most trouble with. Student $\mathrm{C}$ often did not read sources carefully enough, and in some cases misunderstood the source of the information, so that she could not find the correct answer. Student B experienced similar difficulties during practice session three: while his search queries were good he was so eager to find the answer that he did not consider the information carefully enough, and therefore had trouble finding the answer. This behaviour suggests more attention needs to be given to teaching students to analyse sources.

It is possible that this lack of transfer is because the study only tested the students' information literacy skills in unfamiliar topics, and not familiar ones too. Learners need to master a topic before they can transfer, and trying to teach too many concepts in too short a time can hinder opportunities for transfer (Bransford, et al., 1999). Thus, it could be that the participants had not yet mastered information literacy skills in familiar topics, let alone unfamiliar ones.

This study also suggests that practice without active feedback from a teacher may be an ineffective way to teach information literacy. During the practice sessions, students had little input from the student researcher as they completed the tasks. This was to test whether students could develop information literacy skills through practice alone. This part of the design was based on the concept that students learn independently through practice (DeLay, 1996; 
Piaget, 1964; Salomon \& Perkins, 1989). However, the limited progress of students as a result of these practice sessions suggests independent practice alone is not enough, and students require more guidance from a teacher to help them learn. This is consistent with Vygotsky's (1978) Zone of Proximal Development, which claims that learning is a social process. Furthermore, there is a growing body of evidence that unguided instruction could have a negative impact of learning, compared with guided instruction (Kirschner, 2006). While information literacy concepts were taught via direct instruction lessons, the results suggest this was not enough, and students needed more hands-on help to put this into practice.

Coupled with minimal guidance during the practice sessions was a lack of feedback from the first author during or after the practice sessions. This lack of feedback served a research purpose, which was to test the teaching methods of direct instruction and structured practice alone, without the added method of feedback. However, this had the unintended effect that the participants had little idea as to which aspects of the tasks they were succeeding in, and therefore did not know what they needed to do to answer the questions better. Students received some immediate feedback from Google because if they didn't find the answer, they knew they needed refine their search. However, this type of feedback is only effective if students know what the correct answer is. For example, during practice session two when trying to find out what the oldest continuously inhabited city in the world was, Student C incorrectly answered Varanasi. She got the "answer" from Google's search results without even opening a web page. While this shows a lack of information literacy skills, it also shows that the student had no reason to think Varanasi was incorrect. This could also reflect a flaw in the question, as the correct answer was not clear enough. Regardless, the results indicate that students need more than this basic level of feedback in order to achieve. The need for feedback is well supported by existing research. For students to become active learners who monitor their own progress, teachers need to provide appropriate feedback (Hattie, 2012; Bransford, et al., 1999).

Research into online assessment tools shows giving students effective feedback through the tools can be problematic. Qayyum and Smith's (2015) study into assessing online search skills found students benefit from guidance within the online assessment tool, such as prompts that point the student in the right direction. The lack of these scaffolds meant students were not making the best use of the search tools available to them (Qayyum and Smith, 2015). This suggests that tools should be used in conjunction with more social aspects of teaching such as mediation from a teacher, which is consistent with an understanding of learning as a social process (Piaget, 1964; Vygotsky, 1978).

A key finding of this study was that in interventions of this type, students need guidance as they complete the tasks. Feedback from the tool (Google) was not enough in this case, leaving the participants unsure as to how they were progressing. Future studies could focus on how practice with the input of a teacher could help them transfer information literacy skills. Future studies could also explore the potential for information literacy to be embedded into the curriculum rather than taught as a standalone topic, as there is a growing body of research to support this method (Scott \& O’Sullivan, 2005; Fabbi, 2015).

\section{References}

American Library Association. (2000). Information Literacy Competency Standards for Higher Education. Retrieved from http://arizona.openrepository.com/arizona/bitstream/10150/105645/1/standards.pdf

Andrews, L. (2002). Transfer of Learning: A Century Later. Journal of Thought, 37(2), 63-72.

Bransford, J.D., Brown, A. L., \& Cocking, R. R. (Eds.) (1999). How people learn: Brain, mind, experience and school. Washington, DC: National Academy Press. Retrieved from http://www.csun.edu/ SB4310/How\%20People\%20Learn.pdf

Breivik, P. S. (2005). 21st century learning and information literacy. Change: The Magazine of Higher Learning, 37(2), 21-27. DOI: 10.3200/CHNG.37.2.21-27

Candy, P. (2002). Lifelong learning and information literacy. Retrieved from http://citeseerx.ist.psu.edu/viewdoc/download?doi=10.1.1.119.5676\&rep=rep1\&type= pdf

Chu, S. K., Tse, S. K., \& Chow, K. (2011). Using collaborative teaching and inquiry project- based learning to help primary school students develop information literacy and information skills. Library \& Information Science, $33,132-143$.

DeLay, R. (1996). Forming Knowledge: Constructivist Learning and Experiential Education. Journal of Experiential Education, 19(2), 76-81. DOI: 10.1177/105382599601900204.

Doyle, C. S. (1992). Outcome Measures for Information Literacy within the National Education Goals of 1990. Final Report to National Forum on Information Literacy. Summary of Findings.

Fabbi, J. L. (2015). Fortifying the Pipeline: A Quantitative Exploration of High School Factors Impacting the Information Literacy of First-Year College Students. College \& Research Libraries, 76(1), 31-42.

Gross, M., \& Latham, D. (2007). Attaining information literacy: An investigation of the relationship between skill level, self-estimates of skill, and library anxiety. Library \& Information Science Research, 29(3), 332-353.

Hattie, J. (2012). Visible learning for teachers: maximising impact on learning. Routledge: New York. 
Head, A. J. (2013). Learning the ropes: How freshmen conduct course research once they enter college. Project Information Literacy Research Report: "Learning the Ropes".

Katz, I. R. (2007). Testing information literacy in digital environments: ETS's iSkills assessment. Information technology and Libraries, 26(3), 3-12.

Kirschner, P. A., Sweller, J., \& Clark, R. E. (2006). Why Minimal Guidance During Instruction Does Not Work: An Analysis of the Failure of Constructivist, Discovery, Problem- Based, Experiential, and Inquiry-Based Teaching. Educational Psychologist, 41(2), 75-86.

Kovalik, C. (2013). Information Literacy and High School Seniors: Perceptions of the Research Process. School Library Research, 16, 1-26.

Lei, P.-L., Lin, S. S. J., \& Sun, C.-T. (2013). Effect of Reading Ability and Internet Experience on Keyword-based Image Search. Educational Technology \& Society, 16(2), 151- 162.

Lenox, M. F., \& Walker, M. L. (1993). Information literacy in the educational process. The Educational Forum, $57(3), 312-324$.

Mackey, T. P., \& Jacobson, T. E. (2010). Reframing information literacy as a metaliteracy. College \& Research Libraries. Retrieved from http://crl.acrl.org/content/early/2010/04/29/crl-76r1.full.pdf+html

Manuel, K. (2002). Teaching Information Literacy to Generation Y. Journal of Library Administration, 36(1-2), 195-217. DOI: $10.1300 / J 111 v 36 n 01 \_12$

Markless, S., \& Streatfield, D. R. (2007). Three decades of information literacy: redefining the parameters. Change and Challenge: Information Literacy for the Twenty-first Century, 15-36. Adelaide: Auslib Press.

Martin, C. M., Garcia, E. P., \& McPhee, M. (2012). Information Literacy Outreach: Building a High School Program at California State University Northridge. Education Libraries, 34(1-2), 34-47.

Mery, Y., Blakiston, R., Kline, E., Sult, L., \& Brewer, M. M. (2010). Developing an Online Credit IL Course for a Freshman Writing Program in a University Setting. Best Practices for Credit-Bearing Information Literacy Courses, 77-92.

Ministry of Education. (2007). New Zealand Curriculum. Retrieved from http://nzcurriculum.tki.org.nz/The-New-Zealand-Curriculum

Ministry of Education. (2013). New Zealand Curriculum Guides. Retrieved from http://seniorsecondary.tki.org.nz/Social-sciences/Geography

Ministry of Education. (2015). Deciles. Retrieved from http://www.education.govt.nz/school/running-aschool/resourcing/operational- funding/school-decile-ratings/

New Zealand Qualifications Authority. (2015). Geography subject resources. Retrieved from http://www.nzqa.govt.nz/qualifications- standards/qualifications/ncea/subjects/geography/levels/

O’Sullivan, M. K., \& Dallas, K. B. (2010). A Collaborative approach to implementing 21 st Century skills in a High school senior research class. Education Libraries, 33(1), 3-9.

Perkins, D. N. (1986). Thinking frames. Educational leadership, 43(8), 4-10.

Piaget, J. (1964). Development and Learning. Journal of Research in Science Teaching, 2, 176-186.

Probert, E. (2009). Information literacy skills: Teacher understandings and practice. Computers \& Education, 53, $24-33$.

Punch, K. (2009). Introduction to Research Methods in Education. London: SAGE.

Richardson, V. (1997). Constructivist teacher education: Building new understandings. London: Routledge.

Qayyum, M. A., \& Smith, D. (2015). Learning from student experiences for online assessment tasks. Information Research: An International Electronic Journal. 20(2).

Reece, G. J. (2007). Critical thinking and cognitive transfer: Implications for the development of online information literacy tutorials. Research Strategies, 20(2007), 482-493.

Salomon, G., \& Perkins, D. N. (1989). Rocky roads to transfer: Rethinking mechanism of a neglected phenomenon. Educational psychologist, 24(2), 113-142.

Serrell, K. (2009). Finders keepers: A comparative study investigating teaching the Florida research process FINDS model through three different approaches at the elementary school level. University of Central Florida.

Scott, T. J., \& O'Sullivan, M. K. (2005). Analyzing student search strategies: making a case for integrating information literacy skills into the curriculum. Teacher Librarian, 33(1), 21-25.

Thomas, N. P., Crow, S. R., \& Franklin, L. L. (2011). Information Literacy and Information Skills Instruction. ABC-CLIO: Santa Barbara.

Thompson, L., \& Blankinship, L. A. (2015). Teaching Information Literacy Skills to Sophomore-Level Biology Majors. Journal of microbiology \& biology education, 16(1), 29. 
Varlejs, J., \& Stec, E. (2014). Factors Affecting Students' Information Literacy as They Transition from High School to College. School Library Research, 17, 1-24.

Vygotsky, L. (1978). Interaction between learning and development. Readings on the development of children, 34-41.

Walton, M., \& Archer, A. (2004). The web and information literacy: Scaffolding the use of web sources in a project-based curriculum. British Journal of Educational Technology, 35(2), 173-186.

Webber, S., \& Johnston, B. (2000). Conceptions of information literacy: new perspectives and implications. Journal of information science, 26(6), 381-397.

\section{Appendices}

\section{Appendix 1 - Practice session one, research questions for participants}

1. Of which New Zealand band was Malcolm Green the drummer during the 1970s and 1980s? (Correct answer: Split Enz)

2. The Hindu Kush mountain range extends 500 miles westward from Pakistan to what country? (Correct answer: Afghanistan)

3. Which film won the Oscar for Best Picture in 1994? (Correct answer: Schindler's List)

4. What name is given to the Jewish candlestick with special religious meaning? (Correct answer: Candelabra)

5. What was the number one-selling single in New Zealand in 2009? (Correct answer: I Gotta Feeling by Black Eyed Peas)

\section{Appendix 2 - Practice session two, research questions for participants}

1. Of all the countries in the world, which one gets most of its energy from renewable sources? (Correct answer: Lethoso)

2. Which city is the oldest continuously inhabited city in existence? (Correct answer: Damascus)

3. Based on sports club membership numbers, what is the third-most popular sport in Denmark? (Correct answer: Gymnastics)

4. In kilometres, how long is the border between the USA and Canada? (Correct answer: 5,525 miles, or 8,891 kilometres)

5. Which European city - famous for its arts and culture - was founded in 1703 by Peter the Great? (Correct answer: St Petersburg)

\section{Appendix 3 - Practice session three, research questions for participants}

1. Which sports ground, formerly the home of Rugby League in Auckland until it closed in 2002, is now home to a block of apartment buildings? (Correct answer: Carlaw Park)

2. During which war did the Battle of Britain occur? (Correct answer: WW2)

3. In what year did Robert Laidlaw found the Farmers Trading Company? (Correct answer: 1909)

4. On which road was James Dean driving when he died on September 30, 1955? (Correct answer: Highway 46 in California)

5. Which model of car was the most popular in New Zealand in 2014? (Correct answer: Toyota Corolla)

\section{Appendix 4 - Practice session four, research questions for participants}

1. Liza Minelli is a successful Hollywood actor with a career spanning five decades. In which iconic film did her mother play the leading role? (Correct answer: Wizard of $\mathrm{Oz}$ )

2. Who won the seat of Epsom at the 2011 New Zealand general election? (Correct answer: John Banks)

3. Which music festival, first held in New Zealand in 1994, was held for the final time in 2014? (Correct answer: Big Day Out)

4. During which Olympic Games did Jesse Owens win gold medals in the $100 \mathrm{~m}, 200 \mathrm{~m}$ and $400 \mathrm{~m}$ relay running races? (Correct answer: Berlin 1936)

5. In August 2015, Ngapuhi iwi leader Sonny Tau pleaded guilty to possessing what type of endangered native New Zealand bird? (Correct answer: Kereru) 